\title{
Educação e migração haitiana: um estudo de caso a partir de Galtung e Fanon
}

\author{
Education and haitian migration: A case study based on Galtung and Fanon
}

Lucas Rech da Silva $\odot$

Pontifícia Universidade Católica do Rio Grande do Sul (PUCRS), Porto Alegre, RS, Brasil.

\section{Editor \\ Alexandre Anselmo Guilherme PUCRS, RS, Brasil \\ Editor Assistente \\ Cibele Cheron \\ PUCRS, RS, Brasil \\ Editores Associados \\ Bruno Antonio Picoli \\ Universidade Federal da Fronteira Sul, Chapecó, SC, Brasil \\ Pricila Kohls dos Santos \\ Universidade Católica de Brasília, \\ Brasília, DF, Brasil \\ Renato de Oliveira Brito \\ Universidade Católica de Brasilia, \\ Brasilia, DF, Brasil \\ Elisa Ustarroz \\ PUCRS, Porto Alegre, RS, Brasil}

\section{ISSN 2179-8435}

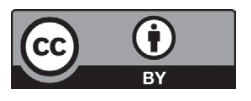

Este artigo está licenciado sob forma de uma licença Creative Commons Atribuição 4.0 Internacional, que permite uso irrestrito, distribuição e reprodução seja corretamente citada.

http://creativecommons.org/licenses/by/4.0/deed.pt_BR

\section{RESUMO}

O trabalho aqui apresentado é resultado de um estudo de caso, realizado com duas jovens haitianas estudantes de Ensino Médio, que teve como objetivo analisar as diferentes expressões de violência de seus processos migratórios e seu cotidiano no Brasil. A análise qualitativa ocorreu através do software NVivo e considerou as interseccionalidades que emergiram e as correlações das violências (física, estrutural, cultural e psicológica) encontradas. Dentre as diferentes violências, que são aprofundadas nas concepções dos autores Johan Galtung e Frantz Fanon, apenas a física não está explícita nos resultados, mas até mesmo ela é problematizada. A pesquisa mostrou que escola pode, em certos casos, agravar as violências inerentes aos processos migratórios se não as discutir e invisibilizar a existência da diversidade em seu interior.

Palavras-chave: Educação. Migração haitiana. Violência. Ensino Médio. Inclusão.

\section{ABSTRACT}

The work presented here is the result of a case study carried out with two Haitian high school students, whose objective was to analyze the different expressions of violence in their migratory processes and their daily lives in Brazil. The qualitative analysis took place through NVivo software and considered the intersectionalities that emerged and the correlations of the violence (physical, structural, cultural and psychological) found. Of the different violence, that are deepened into the authors Johan Galtung and Frantz Fanon, only physics is not explicit in the results, but even it is problematized. The research shows that school can, in certain cases, aggravate the violence inherent in migratory processes if is not discuss then and make invisible the existence of diversity inside the school space.

Keywords: Education. Haitian migration. Violence. High school. Inclusion. 


\section{Introdução}

preocupação com os processos migratórios nos mais diversos campos do conhecimento vêm crescendo nos últimos anos. Desde as ciências humanas, passando pelas sociais aplicadas e a área da saúde, são inquietantes as diferentes dificuldades que esses fenômenos acarretam à pessoa humana, às culturas e às sociedades ao redor do mundo. É fato que a humanidade ocupou o planeta ao longo da história através de inúmeros períodos de migração, mas na contemporaneidade esses vêm tomando proporções preocupantes em virtude do crescimento da xenofobia, da intolerância e do etnocentrismo. Considerando que diferentes setores da sociedade se articulam, portanto, para responder às demandas referentes à temática é natural, também que o Campo de Estudos Migratórios (CEM) se constitua como inter e pluridisciplinar (SAYAD, 1998). Todavia, os diálogos entre o campo da Educação e o campo dos Estudos Migratórios estão, ainda, em processo de construção (BURITICÁ, 2017).

O Brasil foi, como todos os países americanos, constituído de variados processos migratórios durante o período colonial que praticamente dizimou as populações e culturas autóctones em detrimento da cultura europeia. E, não apenas no período colonial, como também no período republicano, os fluxos migratórios sempre estiveram presentes na história do País. Passados mais de 500 anos desde a invasão dos portugueses ainda vivemos os fluxos migratórios internos e externos, por vezes como um país que envia cidadãos ao exterior, mas também como um ponto de chegada de cidadãos de diferentes países vizinhos e de outros continentes. Um dos notáveis fluxos recentes diz respeito à diáspora haitiana (HANDERSON, 2015). Desde o início dessa segunda década do Século XXI, quando o Brasil passa a conferir o visto humanitário ao povo haitiano em virtude do terremoto que abalou a capital do Haiti em 2010, milhares de cidadãos passam a migrar para o Brasil em busca de melhores oportunidade e condições de vida. De acordo com Redin e Minchola (2012, p.38):

Diante da preocupação humanitária, o Conare (Comitê Nacional para os Refugiados) encaminhou as solicitações de refúgio ao Conselho Nacional de Imigração (CNIg), que acolheu a condição de vulnerabilidade dos haitianos através do visto permanente, pelo viés humanitário, denominando-o de visto humanitário.

Ainda, uma pesquisa publicada pelo Instituto de Pesquisa Econômica Aplicada (IPEA) em todo território brasileiro, nos mostra que dentro desse contexto são os jovens entre 18 e 29 anos a grande maioria das pessoas em situação de mobilidade e sujeitos a diferentes vulnerabilidades de que falam Redin e Minchola. Ou seja, ao somar as condições de juventude e de migração, as vulnerabilidades e precariedades se acumulam. Esse mesmo estudo, que objetivou um "mapeamento dos obstáculos normativos, estruturais e institucionais a partir de uma abordagem fundada 
em direitos" (BRASIL, 2015, p. 19), estabelece três principais eixos de preocupação em relação à vulnerabilidade: gênero; crianças, adolescentes e idosos, e pessoas com deficiências (BRASIL, 2015, p. 36). Segundo a pesquisa, essas categorias são as mais suscetíveis às situações de vulnerabilidade no contexto da mobilidade humana no território brasileiro. A pesquisa ainda confirma que o acesso à educação, no estado do Rio Grande do Sul se constitui como o segundo principal obstáculo do acesso a direitos. Dos vinte e cinco imigrantes entrevistados no estado, $89 \%$ disseram não ter tido acesso à educação e $93,3 \%$ disseram não ter sido possível contar com instituições públicas de Educação (BRASIL, 2015). Dito isso, vale enfatizar que a Declaração Universal dos Direitos Humanos (DUDH), promulgada na Assembleia Geral da Organização das Nações Unidas (ONU) em 10 de dezembro de 1948, da qual o Brasil é signatário, explícita no seu vigésimo sexto artigo que:

1. Todo ser humano tem direito à instrução. A instrução será gratuita, pelo menos nos graus elementares e fundamentais. A instrução elementar será obrigatória. A instrução técnico-profissional será acessível a todos, bem como a instrução superior, esta baseada no mérito.

2. A instrução será orientada no sentido do pleno desenvolvimento da personalidade humana e do fortalecimento do respeito pelos direitos do ser humano e pelas liberdades fundamentais. A instrução promoverá a compreensão, a tolerância e a amizade entre todas as nações e grupos raciais ou religiosos e coadjuvará as atividades das Nações Unidas em prol da manutenção da paz. [...]

Diante desses fatos, o presente artigo analisa um estudo de caso realizado no ano de 2017 em uma escola de Ensino Médio (EM) na cidade de Caxias do Sul - Caxias - com duas jovens estudantes de origem haitiana. Com o intuito de compreender como essas percebiam seus processos migratórios e, sobretudo, sua inclusão ao espaço escolar. A pergunta que orientou o estudo foi: De que forma as estudantes compreendem os seus processos migratórios e a sua inclusão ao sistema de ensino local? Para analisar as questões que permeiam esses processos, dialogamos com Frantz Fanon e Johan Galtung para compreender as diferentes expressões de violência às quais as estudantes estiveram expostas durante o processo migratório e na cidade de destino, logo, a inclusão ao espaço escolar e à cidade é pensada através das violências vividas em ambos processos.

\section{Diálogos teóricos}

Abdelmalek Sayad, teórico dos estudos migratórios, conceitua a migração como um "fato social completo", pois trata-se de um fato que merece ampla reflexão interligando os diversos campos do conhecimento como a história, geografia, sociologia, antropologia, direito, política, economia, linguagem e, incluo aqui, a Educação. 
a imigração é, em primeiro lugar, um deslocamento de pessoas no espaço, e antes de mais nada o espaço físico; nisto, encontra-se relacionado, prioritariamente, com as ciências que buscam conhecer a população e o espaço [...] Mas o espaço do deslocamento não é apenas o espaço físico, ele é também um espaço qualificado em muitos sentidos, socialmente, economicamente, culturalmente, politicamente [...] (SAYAD, 1998, p. 15).

O autor percebe a temática fortemente ligada às questões econômicas, porém amplia essa perspectiva ao indivíduo migrante, a qual não se reduz unicamente aos aspectos econômicos, mas também os fenômenos socioculturais da migração. Ele defende a ideia de que a imigração, desde meados dos anos 1940 e 1950, não é uma decisão meramente individual, mas engloba coletividades e famílias. Essas que, muitas vezes, enfrentam problemas comuns e que a decisão de migrar possibilitaria a diminuição das condições, às vezes, precárias ou caóticas do mercado de trabalho de seu país de origem (caso da migração italiana para o Brasil no século XIX). Logo, migrar não apenas proporcionaria uma melhoria na renda das famílias, mas também minimizaria a incapacidade de mercados de incorporarem a mão de obra excedente presente em alguns países em situação de crise econômica ou abalados por conflitos e desastres ambientais (SILVA, 2018, p. 38).

A migração frequentemente ocasiona um estado de vulnerabilidade, o que necessita ser problematizado. Marques propõe pensar a vulnerabilidade como:

um conceito multidimensional que diz respeito a uma condição de fragilidade material ou moral de indivíduos ou grupos perante riscos produzidos por riscos naturais ou contextos económico-sociais. O termo surge na análise geográfica associada aos riscos e posteriormente nos estudos sobre pobreza, desenvolvimento e mudanças globais. [...] Nas ciências sociais e humanas, a vulnerabilidade social referese aos grupos sociais mais marginalizados de uma sociedade, aqueles que estão excluídos dos benefícios e direitos que todos deveriam aceder num mundo civilizado. Está relacionado a processos de exclusão social, pobreza, discriminação e violação de direitos fundamentais, em consequência do seu nível de rendimento, educação, saúde, localização geográfica, entre outros (MARQUES et al., 2016, p. 163).

É em virtude deste cenário de vulnerabilidade que a inclusão destes jovens imigrantes deve ser pensada na perspectiva de melhor acolhê-los e incluí-los em nossa sociedade. Do contrário permaneceremos assistindo às inúmeras situações de conflitos que ocorrem no Brasil e no exterior, bem como a evasão desses estudantes, pois estarão sujeitos a diversas e perversas formas de violência. As violências sofridas pelas pessoas em situação de mobilidade, como no caso dos migrantes internacionais, são muitas e dos mais variados tipos - como xenofobia, 
racismo e misoginia -, podendo ser dito, ainda, que as imigrantes negras, mulheres e jovens se encontram ainda mais à margem dado aos seus marcadores sociais de diferença (BRAH, 2006). Tendo isso em vista, nos reportamos, inicialmente, aos conceitos de violência de Johan Galtung, violências física, cultural e estrutural aliando a isso, posteriormente, os estudos de Frantz Fanon acerca do tema, abordando então a violência psicológica.

Em sua obra, Galtung tipifica a violência em três categorias interdependentes, sendo elas a violência física violência direta -, a violência cultural e a violência estrutural - violências indiretas. A violência física, chamada "violência visível”, engloba insultos e agressão física - sendo impossível não perceber quando ela acontece. Entretanto tanto a violência cultural como a estrutural podem passar despercebidas, serem cometidas de forma sutil, silenciosa, e é por isso que são consideradas, por Galtung, violências indiretas (SILVA, 2017). Galtung entende que a violência estrutural se expressa primordialmente na violência institucional, ou seja, parte geralmente da esfera pública e institucional que nega direitos básicos a qualquer cidadão ou até mesmo na invisibilização e negligência no atendimento aos cidadãos (precariedade nos serviços de educação, saúde e segurança, por exemplo). Nessa categoria pode-se citar a negligência pública ao negar moradia, saneamento básico, comida e tudo o que pode ferir os direitos básicos dos quais todos os seres humanos devem ter acesso.

A violência cultural, no entendimento de Galtung, é uma forma de violência que está arraigada na cultura de dada sociedade, como por exemplo o racismo, bem como o machismo e a misoginia. Ambas formas de violência são correlatas e estão estruturadas nos valores de determinadas sociedades.

Violência estrutural é um tipo de violência que está presente nas sociedades, tornando-as socialmente injusta (ex.: morte por desnutrição). Violência cultural ocorre em suporte à violência estrutural, mascarando-a (ex.: indiferença ou suporte à violência doméstica) (MORGAN; GUILHERME, 2015, p.3).

Nesse sentido e pensando na influência das diferentes facetas da violência nesse processo de escolarização no EM, cabe ressaltar a interpretação de Frantz Fanon sobre as violências, pois ela completa (mesmo que de uma forma distinta) as noções de Johan Galtung. Fanon foi precursor dos estudos descoloniais. Ao trabalhar como psiquiatra na então colônia francesa Argélia, teve a oportunidade de observar os "dois lados da moeda" entre colônia e metrópole, principalmente durante o processo de independência, podendo refletir sobre as diferentes faces da violência sobre o colonizado, mas também sobre o colonizador e como estas influenciam na conduta, nas noções de certo ou errado, justo e injusto, tanto de colonizados como colonizadores. Esse talvez seja sua principal contribuição, ou seja, pensar o reflexo da violência não apenas na vítima, mas também no agressor. 
Ambos os teóricos, Fanon e Galtung, tem um entendimento conceitual de violência que é muito próximo. Todavia, para Galtung a violência cultural é intrínseca à violência estrutural e ambas estão entendidas como violência indireta, pois não são visíveis aos olhos. Já Fanon leva isso mais a fundo, identificando as implicações da colonização psicológica dos sujeitos (de seus pensamentos, modos de vida e cultura), ou seja, os efeitos da violência indireta de Galtung na saúde psíquica dos colonizados. Fanon adiciona a violência psicológica em sua concepção, mas não a categoriza como direta ou indireta, toda violência é direta, visto que agridem diretamente a psique do ser humano e, logo, também o corpo físico. A violência física, para Fanon, é a forma como o colonizador mantém seu domínio sobre o colonizado e é ela que garante a subordinação da colônia à metrópole. Ainda, comentando no contexto de colonização: “...o estrangeiro veio de outro país e se impôs por meio de armas e maquinários” (FANON, 1963, p. 40) complementa que "esta concepção de violência consiste em machucar e matar seres humanos" e isso é argumentado em várias passagens de Os Condenados da Terra ((FANON, 1963, p. 40, tradução nossa).

A violência psicológica identificada pelo autor é uma forma severa de violência que ataca diretamente a saúde psíquica e emocional do indivíduo. Ela inclui, dentre outros aspectos, a lavagem cerebral, as ameaças e a doutrinação que são usadas para frear a autodeterminação. Mas, ainda, a segregação e a invisibilização podem ser compreendidas como aspectos perversos de uma violência psicológica. No contexto escolar contemporâneo, uma grave faceta dessa violência é o bullying, que pode ocorrer tanto no ambiente escolar como nos ambientes de trabalho e de socialização, mas também as diferentes formas de invisibilizar as diversidades no contexto educativo.

Essa violência à psique agride a noção de individualidade e identidade do sujeito e implica de forma cruel na autoimagem e na autoestima. Veremos que essa é uma das formas mais recorrentes de violência neste estudo de caso e à qual as jovens estudantes imigrantes interlocutoras desta pesquisa estiveram expostas. Escrevendo sobre violência psicológica em "Black Skin, White Masks"1, Fanon afirma que:

Quando o Negro faz contato com o Mundo Branco, uma certa sensibilidade toma lugar. Se sua estrutura psicológica está fraca, observa-se um colapso do ego. O homem Negro para de se comportar como uma pessoa real. O objetivo desse comportamento será o Outro (na aparência do homem branco), para que o Outro sozinho lhe dê valor. Isso é, no nível ético: autoestima (FANON, 1967, p. 60, tradução nossa).

Em Os Condenados da Terra, sobretudo no capítulo 5 "Guerra Colonial e Perturbações Mentais", Fanon descreve inúmeros casos de pacientes, franceses e argelinos (colonos e colonizados) que desenvolveram patologias

1 Pele Negra, Máscaras Brancas, em tradução livre. 
e transtornos mentais produzidas diretamente pela opressão do período colonial (FANON, 1967, p. 212). Morgan e Guilherme comentam que Fanon advoga em prol dos colonizados e oprimidos e que esses devem adotar modelos de educação "anticolonial" que não seja uma representação do colonizador, do opressor e da cultura dominante, pois Fanon entende que, mesmo depois de independente, o colonizado permanece interna e psicologicamente colonizado e apenas através da educação seria possível realizar crítica ao discurso e às práticas de educação etnocêntrica colonizadora (MORGAN; GUILHERME, 2013, p. 11). Evidentemente que, no contexto deste estudo de caso, em que nos debruçamos sobre um fluxo migratório recente, o imigrante-estrangeiro se torna oprimido e o brasileiro um opressor, uma vez que esse já incorporou a lógica colonial.

Ademais, Fanon possui um entendimento similar sobre a violência estrutural de Galtung, como uma forma econômica e sociocultural de violentar a pessoa, ou, especificamente no contexto da colonização, como o saque aos recursos naturais da colônia e sua constante subordinação econômica à metrópole. Essa violência gera a pobreza do colonizado, pois sua riqueza é utilizada apenas em favor do colonizador. Assim, se gera fome e pobreza, estará, de forma severa, agredindo o sujeito em suas necessidades básicas de subsistência, e, invariavelmente, atacará seu modo de viver, sua relação com o ambiente, com o outro e consigo mesmo. Nesse cenário de migração, trata-se, sobretudo, da exploração de sua força de trabalho e daquilo que possuem de mais precioso, o tempo de suas vidas. Viver nessas condições os torna suscetíveis à exploração, pois dependem do seu trabalho. De acordo Helman, as migrações afetam bruscamente a saúde mental e física dos migrantes pois:

[...] ser um migrante, em si, não necessariamente leva a doença mental. Diversos outros fatores também são relevantes, incluindo fatores externos como status empregatício, condições de moradia, e reações da sociedade "hospedeira". Fatores como xenofobia, discriminação, preconceito racial (individual e institucionalizado) [...] contribuem para a má saúde mental e física do imigrante, assim como as condições econômicas e políticas que prevalecem na comunidade hospedeira (HELMAN, 2009, p. 169).

Como já citado, parte significativa desses imigrantes são jovens que percorrem as fronteiras em busca de melhores condições de vida, de bem estar e saúde, fugindo das violências estruturais que assolam seus países, como a miséria, a pobreza e a fome. Para amenizar a vulnerabilidade do percurso desses jovens, para que essas trajetórias possam alcançar novos caminhos para uma vida com dignidade, é necessária uma inclusão respeitosa para com a alteridade e a diversidade. 


\section{Percursos metodológicos}

Os passos iniciais desta pesquisa consistiram-se no contato com as escolas da rede pública estadual através de e-mail e telefone intencionando estabelecer um panorama prévio sobre a existência ou não de matrículas de estudantes imigrantes, qual sua origem, idade e nível de ensino. Foram encontrados nove estudantes em quatro das trinta e oito escolas da cidade, porém apenas duas jovens estudantes haitianas se enquadravam no perfil etário estabelecido a priori: jovens e adultos, em idade entre dezessete e trinta e cinco anos. Esse recorte foi previamente estabelecido em função desse ser o perfil com maior ocorrência de mobilidade (IPEA, 2015). Todos os outros sete estudantes que apareceram na sondagem prévia estavam matriculados nos anos iniciais do Ensino Fundamental.

Esta pesquisa se configurou como um estudo de caso, visto que se debruçou na experiência de migração de duas jovens haitianas em uma escola de Caxias do Sul, RS. Yin (2005, p. 32) entende que "um estudo de caso é uma investigação empírica que investiga um fenômeno contemporâneo dentro do seu contexto de vida real, especialmente quando os limites entre o fenômeno e o contexto não estão claramente definidos". Coutinho e Chaves (2002, p.223), por sua vez, pontuam que: "o estudo de caso não é uma metodologia específica, mas um enfoque dos dados preservando o caráter único do objeto social em estudo". O método das entrevistas guiou-se por princípios de História Oral, configurando-se como uma História Oral Temática, definida por Alberti (2004, p. 18) como:

[...] um método de pesquisa (histórica, antropológica, sociológica, etc.) que privilegia a realização de entrevistas com pessoas que participaram de, ou testemunharam, acontecimentos, conjunturas, visões de mundo, como forma de se aproximar de seu objeto de estudo. [...] produz fontes de consulta (as entrevistas) para outros estudos. [...] Trata-se de estudar acontecimentos históricos, instituições, grupos sociais, categorias profissionais, movimentos, [...] à luz de depoimentos de pessoas que dele participaram.

Por essa razão as fontes foram analisadas de forma entrecruzada, permitindo refletir sobre o contexto das estudantes interlocutoras "não como um tabuleiro de xadrez que tem todos os quadrados iguais, mas muito mais como uma colcha de retalhos, em que os pedaços são diferentes, porém formam um todo coerente depois de unidos" (ALVES, 2008, p. 136). Assim, o diálogo com as mesmas também é uma forma de respeitar sua condição de sujeito e agente de sua própria história.

Em uma entrevista dedicada a permitir que o informante conte sua história de vida, o papel do entrevistador não é perguntar questões a respeito da história, mas apenas permitir que a história seja contada da forma como o informante se sente mais confortável para falar daquilo (WENGRAF, 2004, p. 7, tradução nossa). 
A análise qualitativa, por sua vez, buscou entender as violências que foram enfrentadas pelas estudantes a partir de uma análise crítica e reflexiva. Trata-se, portanto, de um estudo de caso sobre as trajetórias de duas jovens estudantes haitianas residentes em Caxias do Sul, RS, e matriculadas no EM da rede pública estadual. A elaboração do roteiro das entrevistas foi pensado na perspectiva de contemplar uma abordagem transnacional, questionando as jovens estudantes interlocutoras sobre o antes e o agora, o lá e o aqui, tal como aponta Sayad $(2008,2010)$ e, também Guarnizo (2006, p. 81):

O enfoque transnacional entende as migrações como um processo dinâmico de construção e reconstrução de redes sociais que estruturam a mobilidade espacial e a vida laboral, social, cultural e política, tanto da população migrante como de familiares, amigos e comunidades nos países de origem e destino(s).

Além disso, a entrevista semiestruturada foi construída à luz de instrumentos utilizados anteriormente em trabalhos com interlocutores em contexto de mobilidade humana como, por exemplo, a pesquisa supracitada do IPEA. O roteiro também sofreu influência das orientações do Return migration and Development Platform (RDP)- do Robert Schuman Centre for Advanced Studies - European University Institute. Além, como recurso metodológico, foi utilizado o Biographic-Narrative Interpretative Method (BNIM), que segundo Wengraf (2004) deve ocorrer e ser organizado em três distintas sessões. A primeira tem o objetivo de construir um panorama geral sobre a história e a trajetória do participante e é fundamental para a construção do background do interlocutor. Na segunda, partindo do que foi percebido como ponto chave no primeiro encontro, são abordados pontos específicos para que o participante possa, novamente, explanar e aprofundar especificidades. Nesta etapa são abordados esses pontos-chave, também em forma de narrativa e delas são tomadas notas para uma possível terceira sessão. Na terceira é possível abordar questões importantes para resolver dúvidas (WENGRAF, 2004, p. 2-3). A decisão por adotar o BNIM ocorreu em virtude de que este facilita a criação de um vínculo maior com as entrevistadas. A análise, por sua vez, foi centrada em entender as categorias estabelecidas a priori (violência física, cultural, estrutural ou psicológica baseadas em Galtung e Fanon) desde o país de origem até o Brasil. Dessa forma, o instrumento intentou um enfoque transnacional, pois, de acordo com Buriticá (2017, p. 12):

a população juvenil não rompe seus laços com sua origem e com as condições sociais, culturais, políticas e econômicas de seus contextos migratórios particulares que estão influenciando de modo determinante suas trajetórias e as formas como negociam suas filiações identitárias. Assim, é fundamental compreender seus projetos migratórios dentro de um trabalho de campo multi situado origem/destino(s), que, interconectados através das redes dos que se vão e dos que ficam, nos permitam comparar as experiências dos migrantes e dos não migrantes.

Educação Por Escrito, Porto Alegre, v. 10, n. 2, jul.-dez. 2019: e36671 
Os procedimentos da pesquisa foram divididos nas seguintes etapas: (1 1 a $)$ Contato com as autarquias de Educação; (2 $\left.2^{a}\right)$ Contato com todas as escolas de médio e grande porte da rede pública estadual, por e-mail e telefone. Após o contato e a verificação, buscou-se o contato com a escola; ( $3^{\underline{a}}$ ) Visita à escola e o primeiro contato com as estudantes interlocutoras. Nesse momento foi apresentada a pesquisa e os objetivos, além de apresentação do próprio pesquisador e de como ocorreriam os encontros, lhes foi entregue, lido e explicado o Termo de Consentimento Livre Esclarecido para que trouxessem assinado no dia marcado para a primeira fase da entrevista; (4⿳亠丷a $)$ Essa etapa aconteceu em três encontros com as interlocutoras, nas dependências da escola onde estudavam, em horários e dias escolhidos por elas mesmas. Com duração média de 40 minutos cada. As entrevistas semiestruturadas foram gravadas em áudio com o consentimento das estudantes interlocutoras.

\section{Análise}

A análise das narrativas, finalizadas as transcrições, realizou-se com utilização dos recursos do programa NVivo. Sobre os benefícios do seu uso nas pesquisas em ciências humanas e sociais, Fleury et al. $(2015$, p. 2) apontam que "dizem respeito sobretudo à possibilidade de, ao agilizar a realização de tarefas mecânicas, liberar tempo para que o pesquisador se dedique às tarefas críticas como exploração e investigação dos dados". Os trechos das narrativas onde as estudantes explicitaram, ou mantinham de forma implícita, aquilo que compreendemos como uma expressão de violência, dentro dos conceitos de Galtung e Fanon, foram categorizados em nós no software NVivo.

Após essa etapa, em cada nó (violência estrutural, violência cultural, violência psicológica e violência física) se abriram as subcategorias relativas ao momento em que apareciam, ou seja, se ocorreram no Haiti, no Brasil ou se estavam atreladas ao processo migratório. Cabe ressaltar que algumas referências podem compreender mais de uma subcategoria, pois pode ter acontecido aqui, mas estar relacionada ao processo de mobilidade, bem como o contrário, ter acontecido lá e ser motivador do processo. Esses trechos fazem referência, sobretudo, a questões relacionadas ao gênero, à geração e à origem.

\section{Diálogos e resultados}

A compreensão da diáspora haitiana é fundamental para contextualizar a pesquisa, visto que as duas jovens estudantes migrantes têm suas trajetórias atravessadas por ela. Ou seja, constitui o plano de fundo das trajetórias dessas jovens estudantes. Compreender a diáspora é importante para entender a naturalização desse processo que é, ainda e infelizmente, violento. 
De acordo com a história narrada pela estudante 1, ela tem sua vida atravessada pela diáspora na família desde bem pequena. Segundo ela o pai viveu dez anos na República Dominicana antes de vir ao Brasil. Essa experiência transnacional desde tão pequena naturalizou processo migratório, e de tudo que ele acarreta, como algo que apenas "faz parte da vida". Mesmo que desse processo possam resultar dificuldades, encará-lo como algo corriqueiro ou que "é da vida", nas palavras de uma das estudantes, possibilita uma aceitação ou naturalização das violências às quais essas jovens haitianas e seus familiares estiveram expostos. O mesmo percurso não acontece com a estudante interlocutora 2, pois o Brasil e o pai são as primeiras experiências diaspóricas na família nuclear, ou seja, mesmo que as diáspora estivesse presente na comunidade, a possibilidade de migrar para o Brasil foi a estreia da família no contexto da diáspora.

Entender as razões da diáspora haitiana é indispensável para refletir crítica e compreensivamente os diferentes olhares deste povo sobre o mundo e as características das relações que este estabelece com os locais de migração. De acordo com Handerson (2015, p. 54), o termo diáspora "dá forma, sentido e constitui o mundo social haitiano" e, ainda, está "associado à mobilidade transnacional como constitutiva da trajetória de vida das pessoas e dos horizontes de possibilidades delas". De tal modo, o termo diáspora assume diferentes formas e significados para o povo haitiano, não dizendo respeito apenas à mobilidade propriamente dita, mas também a aquilo que a ela se relaciona, ou seja, desde o próprio sujeito até suas posses, propriedades, hábitos e perspectivas provenientes da diáspora.

No contexto da cultura haitiana, a diáspora se configura não apenas como uma mobilidade almejada pelos sujeitos e famílias, mas também como todo o universo e a cosmovisão que o processo de mobilidade implica. Migrar é poder avançar e isso mostra não apenas um esforço individual, mas também coletivo para alçar o indivíduo, sua família e a comunidade a um outro status. Além disso o dyaspora (aquele que migra) haitiano, não deixa de participar da vida social e política do Haiti, visto que, de acordo com Handerson (2015), praticamente a metade da população haitiana vive fora do país e é responsável por parte significativa do dinheiro que circula no país. Percebe-se, então, que o projeto migratório no Haiti não é apenas individual, mas sobretudo coletivo, visto que mobiliza famílias e comunidades. Lançar-se ao exterior é ter a possibilidade de colaborar com a família e a comunidade a sair das condições de violências que ferem parte significativa da população, e portanto, tem raiz e uma forte motivação no pertencimento.

Essa face da cultura haitiana é importante para compreender parte do motivo que leva ao processo migratório e, também, às experiências das mulheres, o lugar por elas ocupado nesse contexto. Na história de ambas ficou claro que sua experiência está diretamente vinculada ao reagrupamento familiar, visto que a figura paterna foi quem deu início ao processo em direção ao Brasil em média um ano antes de que as duas pudessem migrar. Os pais das estudantes, 
imigrantes que conseguiram inserção no mercado de trabalho em Caxias do Sul, um importante polo industrial, tiveram a possibilidade de reagrupar suas famílias, trazendo para o Brasil a esposa e os filhos. É esse o panorama que está ao fundo das vidas das jovens interlocutoras: Haiti, um país com graves problemas sociais que desenvolveu uma cultura diaspórica que define sua cosmovisão, e uma situação juridicamente regular com um visto humanitário que lhes concede alguns direitos civis.

Destarte, cabe realizar também um breve panorama sobre a trajetória dessas estudantes. Ambas são jovens, a primeira com 18 anos e a segunda com 17, à época viviam no Sul do Brasil há três anos e migraram em função do reagrupamento familiar, tendo a figura paterna como a primeira a migrar na família nuclear. Ambas frequentavam escolas católicas de turno integral no Haiti. O trajeto entre Haiti e Brasil foi percorrido de avião por ambas, tendo sua partida em Porto Príncipe, escala no Panamá e Porto Alegre como destino. A primeira se dirige para Caxias do Sul onde o pai já está empregado na indústria enquanto a segunda se dirige à Flores da Cunha, cidade vizinha a Caxias de aproximadamente 30 mil habitantes.

A primeira interlocutora, ao chegar no Brasil, passa aproximadamente um ano reclusa com a mãe e os irmãos em casa por não compreender bem a língua local. Após começar a ter aulas com um amigo da família pertencente a uma Igreja passa, então, a frequentar uma comunidade religiosa e a escola. Esta tem como plano de vida regressar ao Haiti após cursar Medicina no Brasil. A segunda, por sua vez, não pretende ficar no Brasil, tampouco retornar ao Haiti. Gostava da sua vida em Flores da Cunha, mas não lhe agrada a vida em Caxias. De acordo com a sua fala, por ser uma cidade menor, possuía outros amigos haitianos com quem conseguia se comunicar, a sua escola lhe oferecia um atendimento em contraturno para sanar dúvidas e ajudar com tarefas escolares. $\mathrm{O}$ frio e a dificuldade de mobilidade na nova cidade são fatores que a fazem não ter vontade de permanecer ali, tampouco no Sul do País.

De forma sucinta, esse é o background das estudantes. A seguir, apresentamos como resultados deste trabalho de pesquisa a frequência em que percebemos as expressões de violência (física, estrutural, cultural e psicológica) nas narrativas. Obtivemos quatro horas e quinze minutos de gravações em áudios que se transformaram em quarenta e cinco páginas de transcrições analisadas no NVivo. Deste total, foram dezoito trechos em referência à violência estrutural, doze relacionados à violência cultural, treze à violência psicológica e nenhum à violência física. Nos próximos parágrafos comentamos esses resultados.

Foram encontrados 42 trechos que remetem a alguma das categorias de violência. Desses, 5 dizem respeito a mais de uma violência, sendo 1 trecho em que a violência estrutural e a cultural estão diretamente ligadas, $3 \mathrm{em}$ que a violência cultural está atrelada à violência psicológica e um outro em que a violência estrutural está ligada a violência psicológica. 


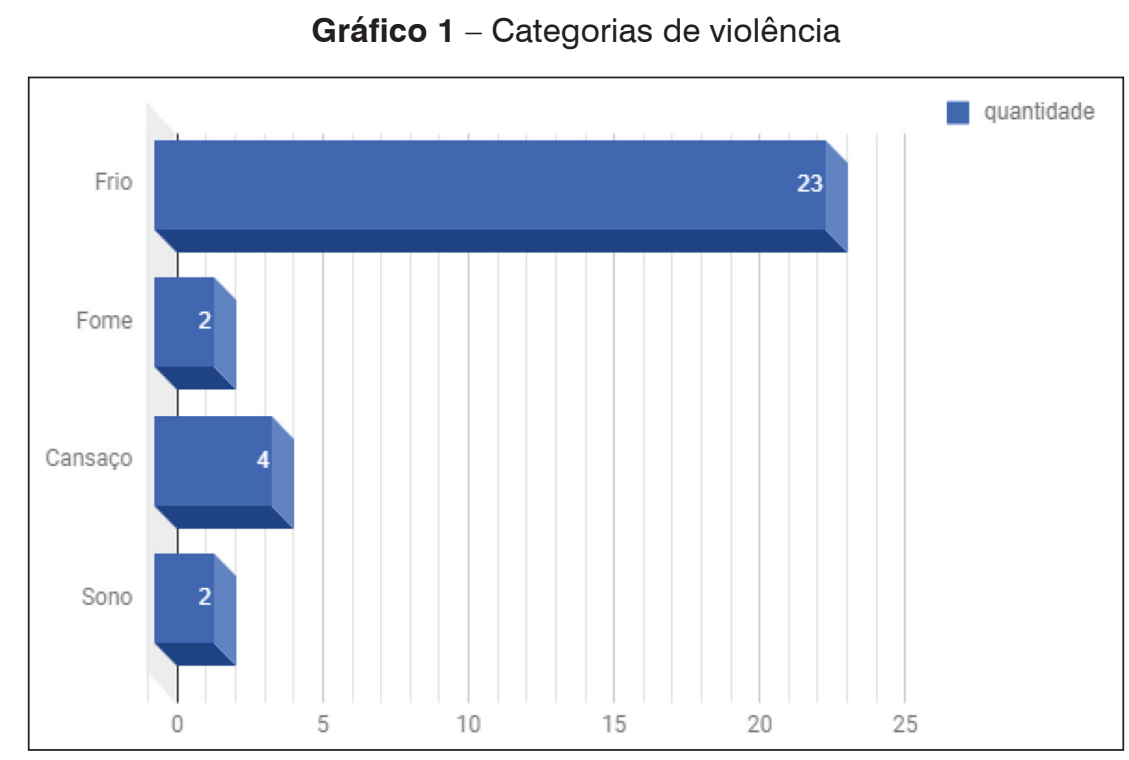

Fonte: Elaborado pelo autor com dados da pesquisa (2018).

No que concerne à análise de cada uma das narrativas no Gráfico 1, é possível verificar que nas falas da interlocutora 1 há maior quantidade de trechos com referência à violência estrutural e cultural, enquanto nas falas da interlocutora 2 há mais referências à violência psicológica. Como demonstrado no gráfico a seguir, apesar de haver uma diferença numérica entre o que foi possível encontrar em uma ou na outra, essa é relativamente pequena, demonstrando que ambas estão expostas ao mesmo grau de violências neste processo.

Não é possível dizer que uma ou outra está mais exposta a uma ou outra violência, mas é possível dizer que nenhuma das estudantes afirmou categoricamente ter sido vítima de violência física e isso será problematizado. No Gráfico 2 encontra-se a quantidade de referências em que a violência estrutural foi identificada. Deste total, dois têm relações com as outras duas categorias de violência, um para violência cultural na primeira estudante interlocutora e um (01) para violência psicológica na estudante 2. Os trechos se referem à falta de emprego para as mulheres da família (intersecção entre violência estrutural e cultural que resulta na violência psicológica), problemas estruturais da escola como falta de professores e a precariedade das condições de vida. 
Gráfico 2 - Comparativo dos graus de exposição à violência entre as estudantes

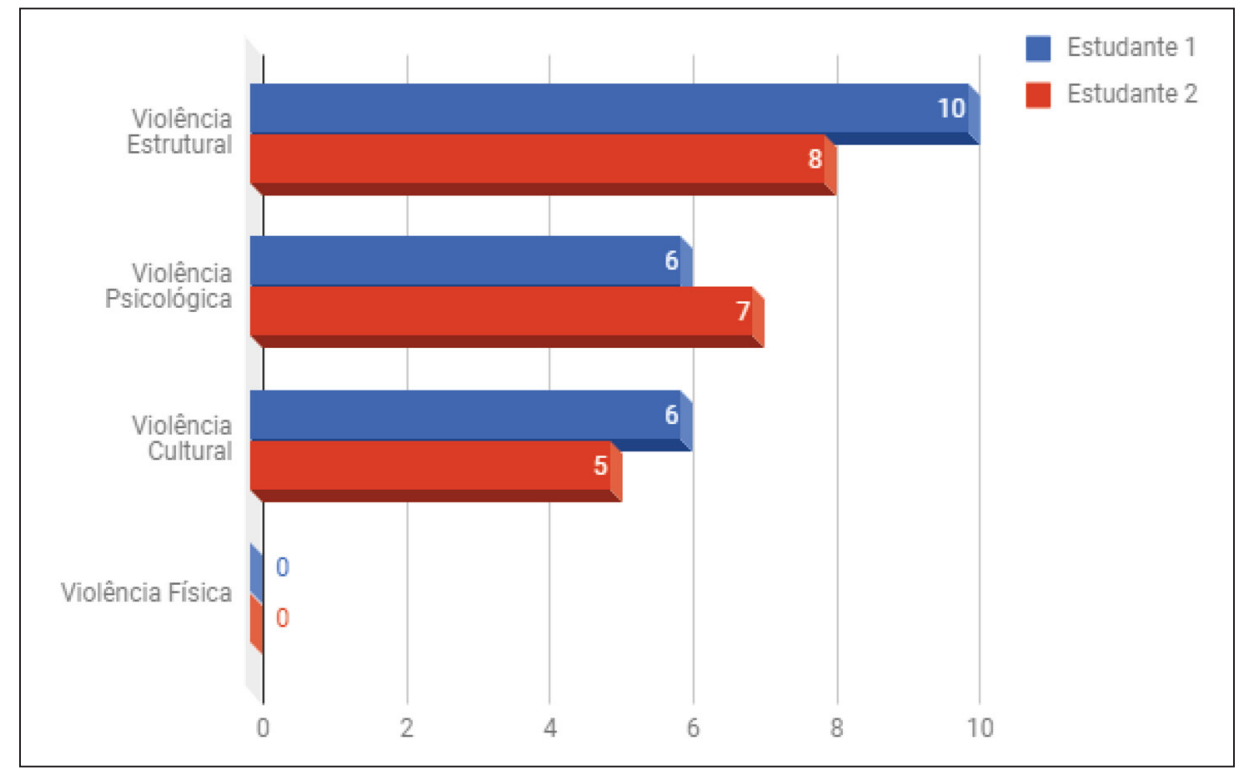

Fonte: Elaborado pelo autor com dados da pesquisa (2018).

Além disso, quando separados, os trechos que fazem referência à violência estrutural são bem limitados ao Haiti (5) ou ao Brasil (13). No que diz respeito ao Haiti, a violência estrutural aparece como motivação principal de migração, ou seja, a busca por oportunidades de trabalho e melhores condições de vida. Porém, é perceptível que no Brasil há mais referências à esta violência e que o processo de mobilidade não atenua este panorama, pelo contrário, o torna mais grave.

Uma das estudantes relata que precisou abandonar o curso de português que participava aos sábados no Centro de Acolhimento ao Migrante (CAM) ${ }^{2}$ por ter sido chamada na escola a recuperar aulas perdidas em função de uma greve de professores. As escolas públicas no RS enfrentam há anos grandes problemas estruturais que influenciam

2 Entidade assistencial que presta serviços de acolhimento e encaminhamento a migrantes na cidade de Caxias do Sul. 
diretamente na vida cotidiana de suas comunidades. A escola, nesta situação, não conseguiu gerir uma demanda particular. É um relato de invisibilização de uma condição sui generis desta estudante, agravando uma situação de violência estrutural e cultural. A greve, no contexto de um Estado em crise, é mais que legítima, mas estas estudantes poderiam recuperar as aulas perdidas com o curso de português (única matéria em que relataram ter mais dificuldade na escola) na entidade que lhes estava oferecendo. A insensibilidade por parte da escola, a coloca em uma posição de reprodução dessas violências.

Em um dos trechos em que identificamos a violência estrutural na narrativa da outra estudante, ela explica que sai de casa por volta de $7 \mathrm{~h} 45 \mathrm{~min}$, vai para o curso de Menor Aprendiz onde permanece até $11 \mathrm{~h} 45 \mathrm{~min}$. Após o curso se desloca diretamente à escola, sem almoçar, onde permanece sem comer até as $18 \mathrm{~h} 45 \mathrm{~min}$. Segundo a estudante, às vezes ela come um pão antes de sair de casa e só come novamente quando chega em casa à noite, não come nada na escola, às vezes sente fome, outras vezes não.

"Entrevistador - O que tu faz? o que tu gosta de fazer? Onde tu vai, onde tu gosta de ir? Aonde tu não gosta de ir?

Estudante 2 - Eu só fica em casa.

E depois a meia dia, eu sai da minha casa, vai na parada pra pegar ônibus e vim pra escola e.. Mas nessa ano, a partir de fevereiro dessa ano eu fui pro curso.

Entrevistador - Curso?

Estudante 2 - Curso de gestão, aprendiz. É. Eu fui a partir de 7:45 até 11:45, e depois vim pra escola e depois pra casa.

Entrevistador - E de 11:45 até o horário de tu vir pra escola? Tu vem direto?

Estudante 2 -É, direto. Se eu vai pra minha casa fica meia dia e trinta e dois/trinta e cinco o ônibus chega. E depois tem que pegar ônibus meia dia e quarenta e quatro, quarenta e cinco. Não tem tempo, não vai dar tempo.

Entrevistador - E tu almoça onde? Aqui na escola?

Estudante 2 - Eu não almoço.

Entrevistador - Tu não almoça?

Estudante 2 - Não. (risos) eu sei, quando eu cheguei aqui. Eu sai da escola 6:25, chego em casa sete e três, sete e dez, alguma coisa assim, e aí eu como, mas não como almoço.

Entrevistador - Tu fica o dia inteiro sem comer?

Estudante 2 - É, sem comer.

Entrevistador - Tu come de manhã antes de sair de casa? 
Estudante 2 - Não, de manhã as vezes eu como um pão.

Entrevistador - E aqui na escola tu não come nada?

Estudante 2 - Não, aqui na escola não. Eu não come na escola.

Entrevistador - E tu não fica com fome?

Estudante 2 - Não, eu já ....

Entrevistador - E tu não traz lanche?

Estudante 2 - Não, às vezes eu como uma bolacha, só. Depois só come a noite."

(Estudante 2, informação verbal)

Não pode-se culpar a escola pelo fato de a estudante passar o dia sem comer, pois uma escola pública brasileira com mais de dois mil alunos, infelizmente, não consegue prever tudo o que acontece ou não com cada um de seus alunos, existem outras demandas que por vezes deixam situações “individuais” passarem despercebidas. Mas há, nesse relato, mais um caso de invisibilização de uma situação que a escola não conseguiu acolher. Nesse contexto é importante que a escola tenha conhecimento da realidade de seus estudantes para que possa tornar a experiência escolar mais acolhedora, para que estes não a abandonem. Todavia, de acordo com a Lei no 11.947 de 2009, a todos os estudantes da Educação Básica pública deve ser oferecida merenda escolar, os recursos para essa alimentação são repassados a estados e municípios pelo Governo Federal. $\mathrm{O}$ fato de uma estudante em fase de desenvolvimento, independentemente da sua origem, passar todo o tempo da escola sem comer nada é, no mínimo, alarmante e nos mostra o quão caótica é a situação das escolas no País. A instituição pública estadual de educação que, por sua vez, também vive uma realidade precária não consegue minimizar essa realidade e ainda exacerba essa situação ao passo que torna invisível a diversidade que emerge nesse contexto. Nesse sentido, não tratar do assunto, não refletir sobre ele é uma forma de perpetuá-lo e dar espaço para que ele se reproduza.

A violência cultural aparece relacionada às questões de gênero e fortemente atrelada à violência estrutural, sobretudo no Brasil, e na naturalização e aceitação das violências a que estão expostas. A violência estrutural ou psicológica é relatada junto com o sentimento de que o fato ou a situação "é da vida, pois a vida é assim" (Estudante 1, citação verbal). Ambas negam ter sido vítimas de racismo ou xenofobia. Porém, na narrativa das duas é possível identificar que acreditam, por exemplo, que o desemprego das mães no Brasil se deve ao fato de serem mulheres imigrantes, bem como a demora que ambas enfrentaram até conseguir um estágio. De acordo com elas, as suas mães estiveram em busca de emprego desde que chegaram na cidade, porém, passados três anos ainda não haviam encontrado trabalho. Elas mesmas apenas conseguiram um estágio após terem se matriculado na escola e com ajuda do CAM. 
Para além da questão laboral, está implícito que as mulheres, no contexto específico das narrativas deste caso, estão submetidas à figura masculina, sem muitas possibilidades, por exemplo, de tomar decisões. Nas narrativas, a decisão de migrar não é delas, mas do pai. Porém, cabe refletir que a migração desses pais também têm como principal motivo uma vida melhor para as suas famílias. Assim, as dinâmicas familiares ganham proporções complexas, pois de um lado há um projeto familiar de busca por melhores condições e, por outro, há projetos que são individuais e esses não necessariamente se traduzem no anseio familiar. Tal problemática é visível, uma vez que seus projetos de vida não estão alinhados aos projetos familiares, visto que uma pretende terminar seus estudos no Brasil e retornar ao Haiti para ajudar as pessoas necessitadas de seu país e, a outra, apenas pretende ir para qualquer lugar onde o frio não seja agressivo.

A questão de gênero carece de discussão, visto que às mulheres são atribuídas diferentes posições nos estudos migratórios. Nos estudos migratórios, durante muito tempo, a presença da mulher esteve invisibilizada ou apenas abordada quantitativamente, como um mero percentual em relação à presença masculina. A posição da mulher nos processos migratórios, quando mencionada, tem sido ligada ao "trabalho do cuidado" ou "trabalho reprodutivo", ou seja, em profissões em que o cuidado (de crianças, idosos, deficientes, pessoas doentes ou lares) é realizado, majoritariamente, pela mulher (CARPENEDO; NARDI, 2013). Essa mudança de perspectiva ocorre no início do terceiro milênio quando o campo dos estudos migratórios passa a realizar uma análise sobre as migrações de mulheres a partir da análise das relações de gênero. Dessa forma, mais do que uma mudança da posição das mulheres nos fluxos migratórios, de coadjuvantes nos processos de mobilidade masculina a protagonistas do seu próprio processo de migração, o que ocorre é uma transformação na análise destes processos por meio das perspectivas de gênero (MARINUCCI, 2007). A migração das mulheres, por vezes, inverte uma posição de subordinação na qual se encontravam nos países de origem ao tornarem-se mantenedoras de suas famílias com o dinheiro ganho no exterior (CARPENEDO; NARDI, 2013; 2017). Handerson e Joseph $(2015$, p. 28) afirmam que, no contexto da migração laboral das mulheres haitianas:

[...] as relações sociais do trabalho, particularmente no setor doméstico, são determinadas pelas diferenças de gênero, de classe, de raça, de origem geográfica e da nacionalidade como dispositivos de discriminação. Assim, elas devem ser pensadas nas diferentes articulações cruzadas e na lógica consubstancial.

Nas trajetórias em análise aqui não se trata de uma migração por escolha, mas sim decorrente do reagrupamento familiar. Verifica-se que há uma subordinação nas relações de gênero e de geração que afeta as vidas das duas estudantes e de suas mães e que se articulam a outros marcadores sociais da diferença, pois essas são negras, 
imigrantes oriundas de um país afetado por conflitos internos, dificuldades econômicas e catástrofes ambientais e que, agora, vivem na periferia de uma cidade fortemente industrializada e marcada culturalmente pela imigração italiana durante o século XIX. Esse marcadores estão estritamente ligados a diferentes violências a que estão expostas. Ambas relatam ter sentido medo e receio antes de saírem de suas cidades, amigos e famílias. Esse sentimento, que transita de lá para cá, acaba por infringir um desgaste emocional e se torna uma vulnerabilidade psicológica. Essa não é a que mais aparece nas narrativas das estudantes, porém é visível que o processo gera um grande desgaste psíquico e que outras violências se agravam. Para além das dificuldades de inserção no mercado de trabalho pela condição de gênero e de origem, há também insegurança financeira, a dificuldade de adaptação ao clima, a dificuldade com a língua, que não permite ser entendida e tampouco entender, a falta de recursos para atividades de lazer. Tudo isso, quando somado a todas as dificuldades da migração, se torna uma carga pesada a ser carregado por essas jovens.

A segunda interlocutora é incisiva em dizer que não gosta da cidade onde está, que sente falta das/os amigas/ os, que é fria, que não há o que fazer, que a mobilidade é difícil e que ali só pretende ficar até concluir os estudos. Carrega nos olhos uma tristeza e uma inconformidade por ter de viver naquele lugar e, paradoxalmente, se refere positivamente à escola e à comunidade onde está, reconhece que no Haiti a vida não seria mais fácil. Para ela, Caxias não foi a primeira cidade no Brasil, mas sim Flores da Cunha, onde havia encontrado amigas/os (também haitianas/ os) com quem, agora, pouco conseguia se comunicar. Além disso, a escola onde estudava antes estava aberta no contraturno para receber as/os alunas/os com dificuldades, especialmente as/os estudantes imigrantes que precisassem de aulas extras de português. Tudo isso teve de ficar pra trás, mais uma vez, após o pai conseguir um emprego em Caxias, o que fez com que a família trocasse de cidade. Em Caxias, a estudante apenas tinha uma amiga na escola (a outra interlocutora), segundo ela, todos os seus colegas são amigas/os, mas de fato, em sua narrativa, o que deixa transparecer é que são relações superficiais, tal qual as relações no trabalho.

A primeira estudante relata que ao chegar em Caxias passou o primeiro ano na cidade sem sair de casa, pois ela e a mãe ainda não compreendiam a língua portuguesa. Depois de passado um ano que um amigo do pai passa a ensinar a língua através de ensinamentos bíblicos. Mais tarde ela relata que, depois da sua dificuldade com a língua portuguesa, seu principal obstáculo foi conseguir se relacionar com as pessoas, especialmente com os colegas na escola, pois se sentia inferior aos seus pares. Muito provavelmente essa noção de inferioridade se deu em virtude da barreira linguística, ou da condição de vulnerabilidade inerente ao processo migratório que pode resultar em uma violência psicológica, causando timidez e constrangimento. Mas não só, pois a dimensão da inferioridade não está sujeita apenas ao isolamento e ao aprendizado da língua. Fanon $(1952,1963,1980)$ é útil aqui para pensar os estigmas internalizados no sujeito negro considerado e tratado como objeto. O colonialismo tem um papel crucial nisso. Para o 
autor, ao vivenciar sua condição alienada, o colonizado busca fugir dos estereótipos construídos na sociedade colonial. A primeira saída é a da assimilação, ou seja, "mudar de pele", tornar-se europeu; a segunda é a revolta aberta contra o colonizador, revolta capaz de transformar-se em revolução. Entre esses dois momentos, ocorre a criação de uma contra mitologia, um "racismo às avessas" por parte do colonizado que, apesar de ainda estar inserido no contexto colonial, apesar de ter um movimento de negação, torna-se dialeticamente a afirmação da identidade em construção.

Ambas estudantes, parecem extremamente tímidas, retraídas, encabuladas. Também transpareciam certo medo, não apenas de se expressar de forma errada (o que é absolutamente normal), mas, sobretudo, medo de falar sobre questões delicadas como o racismo que ambas afirmam não ter presenciado, nem ter sido vítimas. Assim a violência psicológica aparece, principalmente, no que concerne ao sentimento de saudade das pessoas que ficaram, como também do medo da vida em uma nova cultura e em uma realidade tão diferente da sua. As referências à violência psicológica estão, na maioria das vezes, atreladas ao processo migratório, como uma consequência disso, do desgaste emocional e psíquico de ter de trocar de país, deixar para trás uma vida.

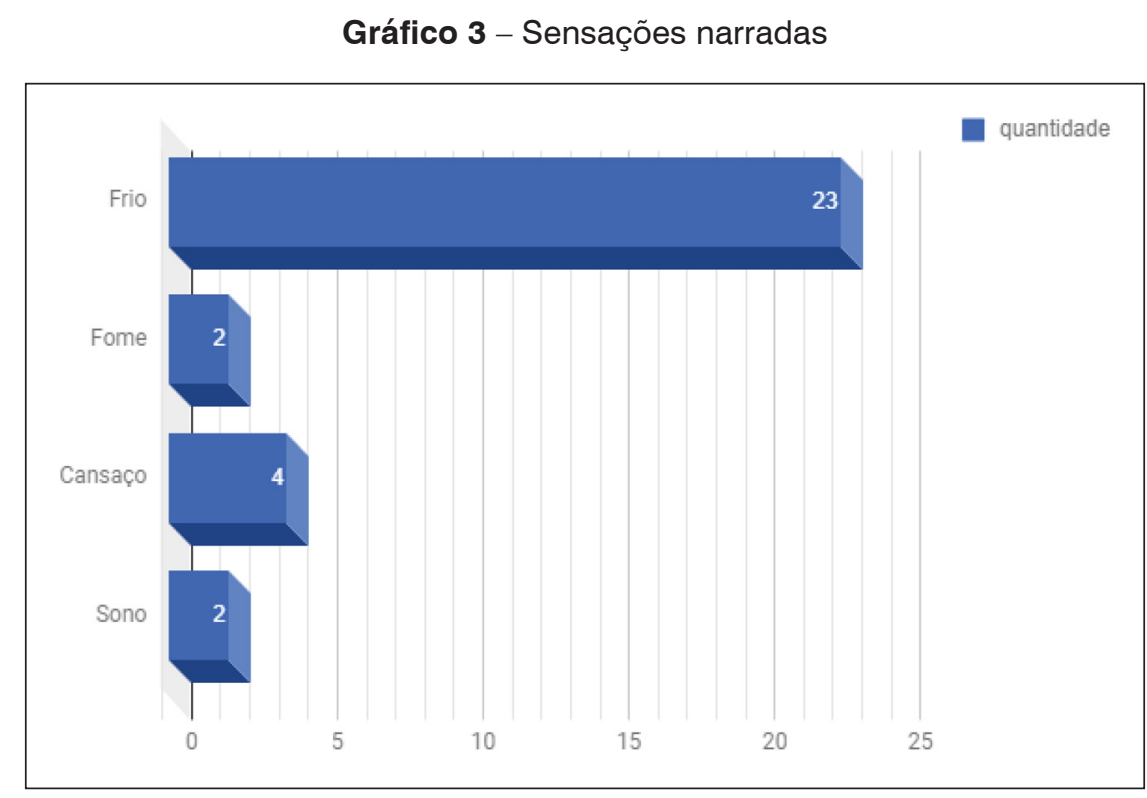

Fonte: Elaborado pelo autor com dados da pesquisa (2018). 
A última categoria, violência física, não é confirmada pela narrativa das estudantes. Ambas afirmam não ter sofrido, em momento algum, qualquer tipo de agressão física vindo de outra pessoa. É preferível acreditar que, de fato, jamais foram vítimas desse tipo de violência antes a pensar que não tenham feito referência a isso por timidez, característica notável de ambas, ou por ainda não terem trabalhado internamente com as situações enfrentadas. Todavia, se pensarmos que fome, sono, cansaço e frio foram sensações que apareceram nas narrativas (conforme o Gráfico 3), podemos pensar que sim, o corpo físico também é agredido pelas outras violências, tal qual demonstrado por Fanon. Assim, mesmo que o corpo não sofra uma agressão vinda de outrem, ele é agredido em decorrência das outras violências que integram o processo.

Há possibilidades diversas de interpretação dos dados apresentados no Gráfico 3. De acordo com as narrativas, elas não estiveram expostas a nenhuma violência física, porém, é possível refletir de forma crítica por qual razão esta violência não aparece. Se, por acaso, talvez essa violência tenha sido naturalizada ou talvez não se sentissem confortáveis para abordá-la com uma pessoa estranha. Vergonha, timidez, dificuldade de expressar assuntos delicados - talvez traumáticos -, são algumas das possíveis causas de ambas não falarem deste tema ou preferirem não o comentar. Dessa forma o processo diaspórico se torna um processo que obriga as pessoas a largarem as suas vidas em seus países para estarem sujeitas a tantas outras violências em outro país em função de seus marcadores de diferença. O problema aqui não está na ação de migrar, mas naquilo que as sociedades fazem disso, transformando algo que deveria ser um direito em um processo traumático.

\section{Considerações finais}

É evidente a existência de intersecções entre as violências a que as estudantes estão expostas, especialmente em função de marcadores de diferença que têm no gênero, no lugar de origem, na raça e na geração aqueles que aparecem majoritariamente. Vimos que a condição de mulher e estrangeira foi um fator dificultador para acessar o mercado de trabalho, logo, a violência cultural e a estrutural são interseccionadas pelo gênero e pelo lugar de origem. Apesar de não ser possível afirmar com base nas narrativas das estudantes, além do gênero e do lugar de origem, talvez a raça também seja um fator que dificulte o acesso dessas mulheres ao mercado em uma cidade de cultura italiana. O processo de mobilidade, motivado por violências estruturais (falta de oportunidades), acaba por ocasionar violências psicológicas (medo, insegurança, sentimento de inferioridade) também atravessadas por violências culturais (machismo, misoginia, racismo). Neste estudo de caso as duas jovens, estudantes, imigrantes negras que vivem social e economicamente vulneráveis, têm estas características como marcadores de sua diferença em uma sociedade de cultura eurocêntrica, machista e fortemente industrializada. Logo, essas características que lhe 
são social e culturalmente impostas se tornam determinantes para as diferentes expressões de violência a que estão expostas.

A impossibilidade de decidir sobre a própria vida e existência é uma supressão de liberdade individual, de ser sujeito de sua própria história, é ter o seu futuro e todas as suas oportunidades reféns de fardos e pressões de todo tipo que não estão sob seu controle e lhe são destinadas como "vontade da vida" ou "porque têm de ser assim". A escola deste caso, de acordo com as narrativas, não oportunizou algum tipo de atividade de acolhimento ou aulas extras de português. Todavia, as estudantes relatam que tanto colegas como professores sempre estiveram dispostos a ajudar nas questões relativas ao estudo e esse talvez seja um ponto importante nas narrativas das estudantes. Ambas explicitam um sentimento de gratidão aos professores e colegas, pela ajuda que lhes prestam com questões curriculares e, principalmente, no que diz respeito à linguagem.

Por fim, percebe-se que o processo de inclusão dessas jovens não aconteceu por meio de práticas de promoção da riqueza da diversidade cultural e da valorização das culturas. Neste estudo de caso ficou perceptível que estamos ainda na dependência de uma sensibilização, daquilo que Barbosa (2010) chama uma Pedagogia da Sociedade Civil. Por mais que isso possa acontecer com algumas pessoas e em alguns lugares, não se pode esperar apenas pela empatia e pela solidariedade, aguardar que esses valores irão emergir sem conflitos. É preciso que as instituições tomem iniciativas que venham ao encontro aos valores enaltecidos na Declaração Universal dos Direitos Humanos onde deveríamos ser iguais em dignidade e direitos, independentemente de origem, sexo, raça, idade.

\section{Referências}

ALBERTI, V. História oral: a experiência do CPDOC. Rio de Janeiro: Instituto de Documentação; Editora da Fundação Getúlio Vargas, 1990. https://doi.org/10.17533/udea.trahs.n12a04

ALVES, N. Nós somos o que contamos: a narrativa de si como prática de formação. In: SOUZA, E. C.; MIGNOT, A. C. V. (org.). Histórias de vida e formação de professores. Rio de Janeiro: Quartet; Faperj, 2008. p. 131-145. https://doi.org/10.12957/ riae.2015.23796

BARBOSA, M. Educação e Desafios da Multiculturalização: uma pedagogia da sociedade civil. Cadernos de Pesquisa, São Luiz, v.40, n. 141, p. 993-1023, 2010. https://doi.org/10.1590/s0100-15742010000300016

BRAH, A. Diferença, diversidade, diferenciação. Cadernos Pagu, Campinas, n. 26, p. 329-376, 2006. Disponível em: http://www. scielo.br/pdf/cpa/n26/30396.pdf. Acesso em: 11 nov. 2017. https://doi.org/10.1590/s0104-83332006000100014 
BRASIL. Ministério da Justiça. Migrantes, apátridas e refugiados: subsídios para o aperfeiçoamento de acesso a serviços, direitos e políticas públicas no Brasil. Ministério da Justiça, Secretaria de Assuntos Legislativos. Brasília, DF: Instituto de Pesquisa Econômica Aplicada, 2015. Disponível em: http://pensando.mj.gov.br/wp-content/uploads/2015/11/PoD_57_web2.pdf. Acesso em: 11 nov. 2017. https://doi.org/10.26668/indexlawjournals/2526-026x/2018.v4i1.4365

BURITICA, María Margarita Echeverri. "Somos muitos, somos diversos e aqui estamos cruzando fronteiras": Reflexões sobre a compreensão dos processos migratórios juvenis. Desidades, Rio de Janeiro, v. 16, p. 9-18, set. 2017.

CARPENEDO, M.; NARDI, H. C. Mulheres Brasileiras na Divisão Internacional do trabalho reprodutivo: construindo subjetividade(s). Revistas de Estudios Sociales, Colombia, n. 45, p. 96 a 109, 2013. https://doi.org/10.7440/res45.2013.08

CREMIM, H.; GUILHERME, A. Violence in Schools: Perspectives (and hope) from Galtung and Buber. Educational Philosophy and Theory, Randwick, p. 1-15, 2015. Early view. https://doi.org/10.1080/00131857.2015.1102038

COUTINHO, C. P; CHAVES, J. H. O estudo de caso na investigação em Tecnologia Educativa em Portugal. Revista Portuguesa de Educação, Portugal, v. 15, n. 1, p. 221-243, 2002. Disponível em: http://repositorium.sdum.uminho.pt/handle/1822/492. Acesso em: 01 nov. 2017. https://doi.org/10.21814/rpe.13921

FANON, F. Black Skin, White Masks. França: Éditions du Seuil, 1952.

FANON, F. The wretched of the Earth. Nova York: Grove Weidenfeld, 1963.

FANON, F. Racismo e Cultura. In: FANON, F. Em defesa da Revolução Africana. Portugal: Sá da Costa, 1980. p. $34-48$. Disponível em: https://afrocentricidade.files.wordpress.com/2016/04/em-defesa-da-revoluc3a7c3a3o-africana-frantz-fanon.pdf. Acesso em: 01 nov. 2017. https://doi.org/10.4000/cultura.2585

FLEURY, L. C. Uso do NVivo em Estudos Rurais. In: RADOMSKY, G. F. W; SCHNEIDER, S.; CONTERATO, M. A. (org.).

Pesquisa em Desenvolvimento Rural: técnicas, bases de dados e estatística aplicadas aos estudos rurais. Porto Alegre: Editora da UFRGS, 2015. p. 297-314.

GAltung, J. Peace: Research, education, action. Copenhagen: Christan Ejlers, 1975. (Essays in Peace Research, v. 1).

GALTUNG, J. Three approaches to peace: Peacekeeping, peacemaking, peacebuilding, Peace, war and defense. Copenhagen: Christian Ejlers, 1976. p. 297-298. (Essays in Peace Research, v. 2).

GALTUNG, J. Peace by peaceful means: Peace and conflict, development, \& civilization. London: Sage Publications \& International Peace Research Association, 1996. https://doi.org/10.4135/9781446221631 
GUARNIZO, L. E. Migración, globalización y sociedad: teorías y tendencias en el siglo XX. In: ARDILA, G. (org.). Colombia: migraciones, transnacionalismo y desplazamiento. Bogotá: CES, 2006. p. 65-112.

GUILHERME, A. A.; SILVA, L. R.; FRAGA, I. A Educação Profissional e sua importância no contexto de migrações laborais: um estudo de caso. In: PARIAT, Marcel; LAFONT, Pascal (org.). Comparaison Plurielle. 2. ed. Paris: Conaissances \& Savoirs, 2017. v. 2, p. 75-94.

HANDERSON, J. Diáspora: Sentidos sociais e mobilidades haitianas. Horizontes Antropológicos, Porto Alegre, ano 21, n. 43, p. 51-78, jan./jun. 2015. https://doi.org/10.1590/s0104-71832015000100003

HANDERSON, J.; JOSEPH, R.M. As Relações de Gênero, de Classe e de Raça: mulheres imigrantes haitianas na França e no Brasil. Revista de Estudos e Pesquisas sobre as Américas, Brasília, DF, v. 9, n. 2, p. 1-33, 2015. https://doi.org/10.21057/repam.v9i2.17266

HELMAN, C. G. Cultura, saúde e doença. Tradução: Ane Rose Bolner. 5. ed. Porto Alegre: Artmed, 2009.

LAGE, M. C. Utilização do software NVivo e m pesquisa qualitativa: uma experiência em EaD. Educação Temática Digital, Campinas, v. 12, nesp. p. 198-226, mar. 2011. Disponível em: https://periodicos.sbu.unicamp.br/ojs/index.php/ etd/ article/ view/1210/1225. Acesso em: 01 nov. 2017. https://doi.org/10.20396/etd.v12i0.1210

MACHADO, I. J. R., KEBBE, V. H., SILVA, C. R. Notas sobre a família transnacional. Revista Interdisciplinar da Mobilidade Humana. Rio de Janeiro, v. 16, n. 30, p. 79-98, 2008.

MARINUCCI, R. Feminização das migrações? Revista Interdisciplinar da Mobilidade Humana, Rio de Janeiro, v. 15, n. 29, p. 1-14, 2007.

MARQUES, T. S.; MATOS, F.; MAIS, C.; RIBEIRO, D. Crise e vulnerabilidade social: uma leitura territorial. In: JORNADAS DE GEOGRAFÍA ECONÓMICA, LOS ESCENARIOS ECONÓMICOS EN TRANSFORMACIÓN, 7., 2016. La realidad territorial tras la crisis económica USC-AGE. [S. l: s. n.], 2016. p. 163-174.

MORGAN, W. J.; GUILHERME, A. A. Martin Buber et Frantz Fanon: Le politique dans l'e'ducation: dialogue ou rebellion. Diogène, Paris, n. 241, p. 35-57, jan./mar. 2013. https://doi.org/10.3917/dio.241.0035

REDIN, G.; MINCHOLA, L. A. B. Proteção dos Refugiados na Declaração de Cartagena de 1984: uma Análise a partir do caso dos Haitianos no Brasil. Revista de Estudos Internacionais (REI), João Pessoa, PB, v. 4, n. 1, p. 20-45, 2013. https://doi.org/10.21783/ rei.v4i1.212

RETURN MIGRATION AND DEVELOPMENT PLATFORM. Manual de Questionário de Entrevista. [S. l.: s. n.], [2016?]. Disponível em: http://rsc.eui.eu/RDP/research-projects/cris/. Acesso em: 02 nov. 2016. 
SAYAD, A. Imigração ou os paradoxos da alteridade. São Paulo: Edusp, 1998.

SAYAD, A. La doble ausencia. De las ilusiones del emigrado a los padecimientos del inmigrado. Barcelona: Anthropos, 2010.

SILVA, L. R. da. A inclusão de Imigrantes no Ensino Médio em Caxias do Sul: um estudo de caso na perspectiva das violências de Galtung e Fanon. 2018. 107 f. Dissertação (Mestrado) - Pontifícia Universidade Católica do Rio Grande do Sul, PUCRS, Porto Alegre, 2018. https://doi.org/10.5783/rirp-9-2015-05-67-88

UNITED NATIONS. International Migration, Racism, Discrimination and Xenophobia. Geneve: Switzerland, 2001. Disponível em: http://www.unesco.org/most/migration/imrdx.pdf. Acesso em: 13 maio 2016.

UNITED NATIONS. Declaração Universal dos Direitos Humanos: adotada e proclamada pela Resolução 217 (III) da Assembleia Geral das Nações Unidas em 10 de dezembro de 1948. Brasília, DF: WHO, 1998. Disponível em: http://unesdoc.unesco.org/ images/0013/001394/139423por.pdf. Acesso em: 20 nov. 2017. https://doi.org/10.1590/s0103-56652008000200015

WENGRAF, T. The Biographic-Narrative Interpretive Method (BNIM). Thousand Oaks: SAGE, 2004.

YIN, R. Estudo de Caso: Planejamento e Métodos. Porto Alegre: Bookman, 2005.

Recebido em:17/12/2019.

Aprovado em: 20/12/2019.

Publicado em: 17/4/2020.

\section{Endereço para correspondência:}

Lucas Rech da Silva

Pontifícia Universidade Católica do Rio Grande do Sul

Av. Ipiranga, 6681, Prédio 8, sala 303-13 - Partenon

97010-082, Porto Alegre, RS, Brasil

\section{Autor:}

Lucas ReCH DA Silva

Doutorando e Mestre em Educação pela Pontifícia Universidade Católica do RS (PUCRS), Porto Alegre, RS, Brasil. É Licenciado em Ciências Sociais -

Universidade Federal de Pelotas.

Orcid: http://orcid.org/0000-0003-1284-3649

E-mail: lucas.rech@gmail.com 